\title{
Evaluation of Modified Fenton procedure for persistent superficial dyspareunia following childbirth
}

\author{
Suganthi Chandru $\cdot$ Tamer Nafee $\cdot$ Khaled Ismail • \\ Chris Kettle
}

Received: 22 March 2009 / Accepted: 10 June 2009/Published online: 27 June 2009

(C) Springer-Verlag 2009

\begin{abstract}
Studies reported that $17-23 \%$ continue to experience superficial dyspareunia at 3 months after delivery and $10-14 \%$ at 12 months. Several referrals to a 'Fenton procedure' for the management of postpartum dyspareunia secondary to scar tissue have been made in the literature, but to our knowledge, the technique has not been adequately evaluated in published medical literature. In this study, 24 women underwent a Modified Fenton procedure for persistent superficial dyspareunia caused by a band of scar tissue or web of skin at the introitus. Fourteen women $(60.8 \%)$ reported complete relief and moderate relief was reported in nine $(39 \%)$. The results were encouraging in the majority of women treated.
\end{abstract}

Keywords Dyspareunia $\cdot$ Modified Fenton $\cdot$ Perineoplasty

\section{Introduction}

Dyspareunia affects many women following childbirth. Studies reported that, although $62-88 \%$ of women resume intercourse by $8-12$ weeks postpartum, $17-23 \%$ continue to experience superficial dyspareunia at 3 months after delivery and $10-14 \%$ at 12 months. One study even reported that $62 \%$ of women experienced dyspareunia at some time during the first 3 months postpartum and $31 \%$ still complained of dyspareunia at 6 months. Postpartum

S. Chandru $\cdot$ T. Nafee $\cdot$ K. Ismail $(\triangle) \cdot$ C. Kettle

Academic Unit of Obstetrics and Gynaecology,

University Hospital of North Staffordshire,

Stoke-on-Trent, UK

e-mail: khaled.ismail@uhns.nhs.net

T. Nafee

e-mail: tamernafee@nhs.net dyspareunia can lead to more complex sexual disorders. Hence, it is important to deal with them promptly and effectively [1-6].

Superficial dyspareunia following childbirth may be physical or psychological. Physical dyspareunia can be secondary to scar tissue formation or poor anatomical reconstruction following perineal trauma [7, 8]. A thin band of scar tissue or web of skin at the introitus is a common cause of superficial dyspareunia. Typically, this causes severe pain during penetration and sometimes splits and bleeds during intercourse [9]. Healing by scar tissue leads to repetition of the problem in subsequent attempts at intercourse.

Conservative approaches, including vaginal dilators and perineal massage, have been reported to provide relief of symptoms in a minority of patients [9]. The original Fenton procedure [10] was described to 'widen a tight vagina'. It involved a transverse incision at the muco-cutaneous junction and raising a vaginal mucosal flap. Next, a longitudinal incision of the perineal skin, perineal body and perineal muscles was made, which stopped short of the external anal sphincter. This was repaired in layers in the transverse plane. This procedure was later modified and was used in the management of scar tissue which resulted from perineal trauma episiotomy or tear. The "Modified Fenton' was not so invasive as the original Fenton procedure and involved dividing the perineum and lower vagina vertically and suturing the incision horizontally.

The aim of this study is to evaluate the 'Modified Fenton' procedure in the management of postpartum dyspareunia caused by scar tissue formation or a web of skin at the introitus that did not respond to conservative measures.

Setting A dedicated multidisciplinary perineal care clinic affiliated to a university hospital. 


\section{Patients and methods}

Women experiencing superficial dyspareunia following childbirth were referred to a multidisciplinary perineal care clinic for detailed history and examination. Those women who were noted to have a band of scar tissue or a web of skin at the posterior fourchette were initially advised to perform perineal massage with vitamin-E cream or sweet almond oil for a period of 6-8 weeks. Women who reported no improvement at the end of 8 weeks underwent a Modified Fenton procedure. This involved a $1.5-2.0-\mathrm{cm}$ longitudinal incision and dissection of underlying tissues to release the area of scarring, followed by transverse suturing in one or two layers according to the depth of the wound using Vicryl Rapide 3/0 suture material (Fig. 1).

Twenty-four women underwent a Modified Fenton procedure for persistent superficial dyspareunia caused by a band of scar tissue or web of skin at the introitus. The procedure was performed mainly under local anaesthesia and general anaesthesia was used only in selected cases depending on the extent of scarring or if it was requested by the women. The women $(n=24)$ were admitted as day cases during the period of March 2003 to December 2006 and the procedures were performed by the same surgeon. All women were reviewed in the perineal care clinic at 6 weeks postoperatively.

\section{Results}

All 24 women who underwent surgery were included in this series. The median age was 27 years (range 2037 years). Sixteen patients (64\%) were primiparous. Time since last childbirth was less than 6 months in $33 \%(n=8)$, between 6 and 12 months in 33\% $(n=8)$ and more than 12 months for the rest. Nineteen women (79\%) had spontaneous vaginal delivery and the remaining five women had an assisted vaginal delivery (ventouse or forceps). It was documented in the medical notes that $29 \%(n=7)$ women sustained a third-degree tear and 58\% $(n=14)$ women had a right mediolateral episiotomy and/or

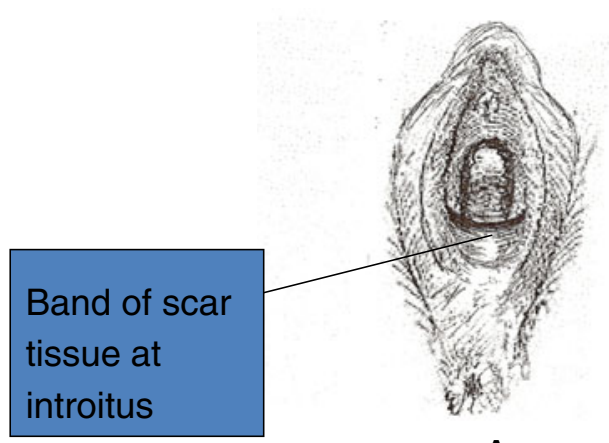

A

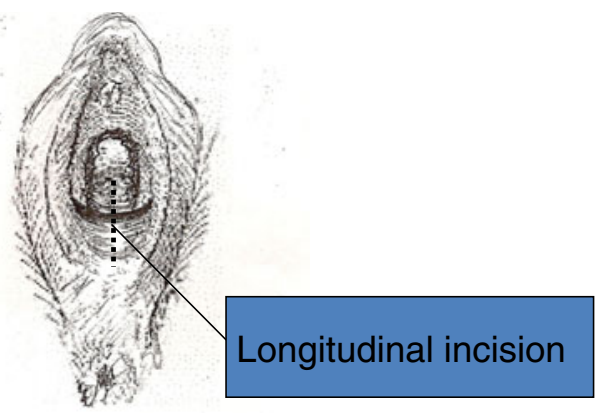

B

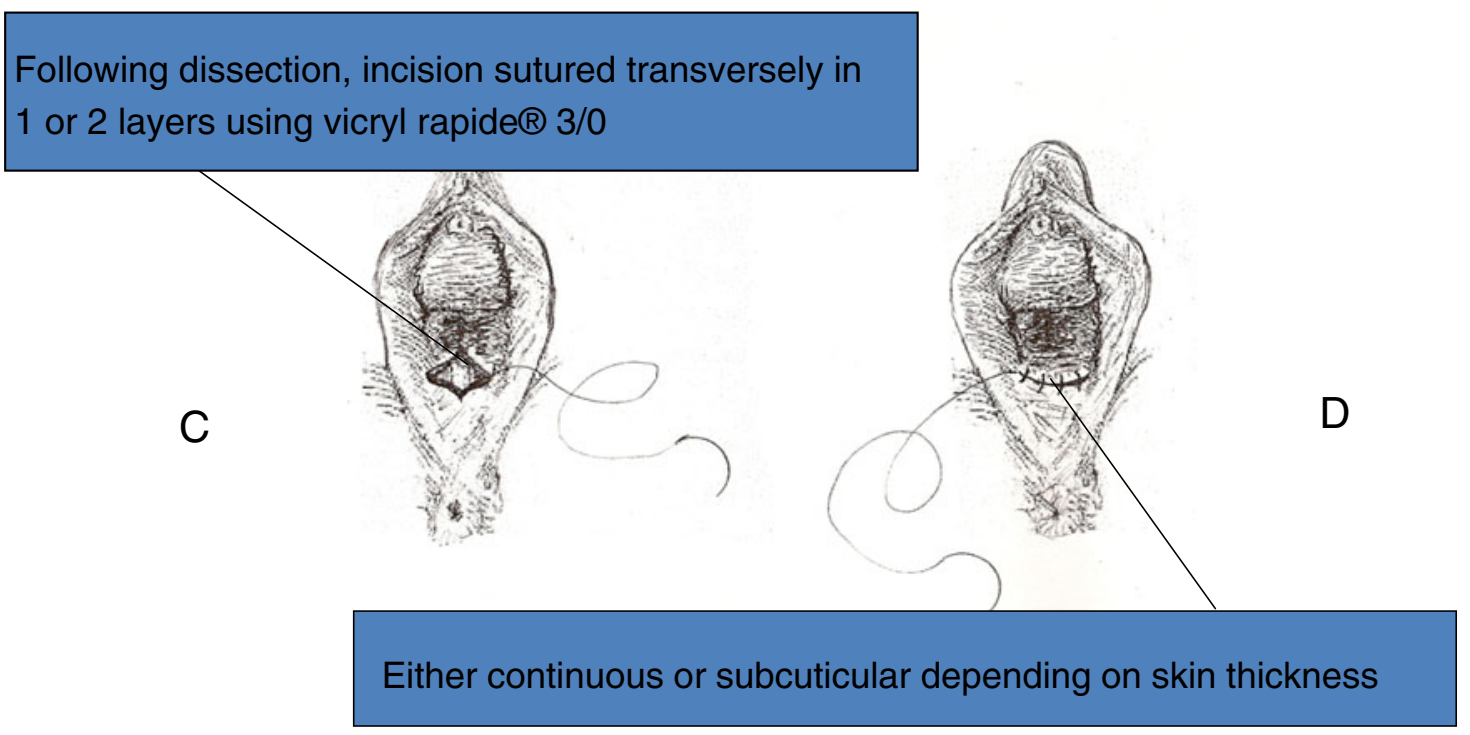

Fig. 1 Modified Fenton's procedure. a Position of the thin band of scar tissue at the posterior fourchette. b Longitudinal incision line. c Suturing in transverse plane. d Final suture line 
second degree tear and $13 \%(n=3)$ had either labial or first degree perineal tear.

All 24 women in the study complained of superficial dyspareunia; one patient was not able to resume penetrative sex and another complained of loss of libido.

In $71 \%(n=17)$ of women, the procedure was done under local anaesthesia and $29 \%(n=7)$ under general anaesthesia. All the women were discharged on the same day and none of them encountered any intra- or postoperative complications.

Three-monthly follow-up was available for 23 out of 24 women up to 12 months (one patient was lost to follow-up). Fourteen women $(60.8 \%)$ reported complete relief and moderate relief was reported in nine $(39 \%)$. In one case, surgery was repeated three times and only managed to achieve moderate relief. Three out of eight women who reported partial relief continued perineal massage; two of these reported significant improvement and follow-up was lost in one case.

\section{Discussion}

Several referrals to a 'Fenton procedure' for the management of postpartum dyspareunia secondary to scar tissue have been made in the literature, but to our knowledge, the technique has not been adequately evaluated in published medical literature. Ganapathy and colleagues [11] recently reported a retrospective case series of 103 women who had secondary repair of the perineum following childbirth. Their study, however, mainly focused on identification of intrapartum and primary repair risk factors associated with the childbirth related perineal trauma

Several surgical procedures for management of superficial dyspareunia were described in relation to vulval vestibulitis, a pathology which is different from postpartum superficial dyspareunia secondary to scar tissue formation. These procedures often involve extensive dissection and are a modification of original perineoplasty described by Woodruff, which entailed excision of all vestibular tissue to the para-urethral regions $[12,13]$. Kehoe and Lusley described a modification to target the posterior vestibule only, but still involved dissection and mobilisation of the lower vaginal wall [14]. The extent of dissection described in these procedures is often extensive enough to incite re-scarring and the need for repeat procedures. The surgical technique referred to in the study by Ganapathy et al. is similar to the technique described in our study, albeit most of the procedures performed in our series were under local anaesthetic. However, we prefer to use the term 'Modified Fenton', following the description by Monaghan et al. [10], because it describes a specific surgical procedure rather than the generic terminology of secondary repair or perineoplasty.
In our small case series, the majority of women reported considerable relief of symptoms.

The limitation of this study is that it was a case series and, due to lack of treatment randomisation, the findings may be biased and overoptimistic [15]. Randomised controlled trials are therefore needed to evaluate the effectiveness of this procedure for superficial dyspareunia.

Modified Fenton's procedure is simple and can be done as a day procedure under a local anaesthesia which allows conscious pain mapping prior to surgery. The extent of dissection was limited and tailored to each individual case. The results were encouraging in the majority of women treated. We consider that excluding non-organic causes of postpartum dyspareunia and limiting surgical intervention to women who failed to respond to adequate and proper conservative management may be crucial to the success of the procedure. Undoubtedly, results of this procedure will depend on appropriateness of case selection.

Conflict of interest There is no actual or potential conflict of interest in relation to this article.

\section{References}

1. Barrett G, Pendry E, Peacock J, Victor C, Thakar R, Manyonda I (2000) Women's sexual health after childbirth. BJOG 107(2):186-195

2. Kettle C, Hills RK, Jones P, Darby L, Gray R, Johanson R (2002) Continuous versus interrupted perineal repair with standard or rapidly absorbed sutures after spontaneous vaginal birth: a randomised controlled trial. Lancet 359(9325):2217-2223

3. Glazener CM (1997) Sexual function after childbirth: women's experiences, persistent morbidity and lack of professional recognition. Br J Obstet Gynaecol 104(3):330-335

4. Gordon B, Mackrodt C, Fern E, Truesdale A, Ayers S, Grant A (1998) The Ipswich Childbirth Study: 1. A randomised evaluation of two stage postpartum perineal repair leaving the skin unsutured. Br J Obstet Gynaecol 105(4):435-440

5. Isager-Sally L, Legarth J, Jacobsen B, Bostofte E (1986) Episiotomy repair-immediate and long-term sequelae. A prospective randomized study of three different methods of repair. Br J Obstet Gynaecol 93(5):420-425

6. Grant A, Gordon B, Mackrodat C, Fern E, Truesdale A, Ayers S (2001) The Ipswich childbirth study: one year follow up of alternative methods used in perineal repair. BJOG 108(1):34-40

7. Klein MC, Gauthier RJ, Robbins JM, Kaczorowski J, Jorgensen SH, Franco ED et al (1994) Relationship of episiotomy to perineal trauma and morbidity, sexual dysfunction, and pelvic floor relaxation. Am J Obstet Gynecol 171(3):591-598

8. Signorello LB, Harlow BL, Chekos AK, Repke JT (2001) Postpartum sexual functioning and its relationship to perineal trauma: a retrospective cohort study of primiparous women. Am J Obstet Gynecol 184(5):881-888

9. Kettle C, Ismail KMK, O'Mahony F (2005) Dyspareunia following childbirth. The Obstetrician and Gynaecologist 7:245249 
10. Monaghan JM, Lopes T, Naik R (2004) Bonney's gynaecological surgery, 10th edn. Wiley-Blackwell, New York

11. Ganapathy R, Bardis NS, Lamont RF (2008) Secondary repair of the perineum following childbirth. J Obstet Gynaecol 28(6):608-613

12. Woodruff JD, Genadry R, Poliakoff S (1981) Treatment of dyspareunia and vaginal outlet distortions by perineoplasty. Obstet Gynecol 57(6):750-754
13. Friedrich EG Jr (1987) Vulvar vestibulitis syndrome. J Reprod Med 32(2):110-114

14. Kehoe S, Luesley D (1999) Vulvar vestibulitis treated by modified vestibulectomy. Int J Gynaecol Obstet 64(2):147-152

15. Pocock SJ (2008) The justification for randomised controlled trials. Clinical trials: a practical approach. Wiley, Chichester, pp $50-65$ 